\title{
The Impact of DTCA on the Physician-Patient Relationship: An Empirical Investigation in Jordan
}

\author{
Assad Hammad Abo-Rumman \\ Associate Professor of Marketing, Faculty of Economics and Administrative Science \\ Applied Science University, Amman, Jordan \\ E-mail: assd_aborumman@asu.edu.jo or assdham200@hotmail.com \\ Ala'Eddin Mohammad Khalaf Ahmad (Corresponding author) \\ Assistant Professor of Marketing, Faculty of Economics and Administration \\ King AbdulAziz University, Jeddah, Kingdom of Saudi Arabia \\ Tel: 966-56-852-7444Ｅ-mail: aladdin.a.n@hotmail.com
}

Received: July 16, $2011 \quad$ Accepted: December 5, $2011 \quad$ Published: April 1, 2012

doi:10.5539/ijms.v4n2p167 URL: http://dx.doi.org/10.5539/ijms.v4n2p167

\begin{abstract}
Purpose - The purpose of this research is to investigate the feasibility of adoption of direct to consumer advertising (DTCA) in the Jordanian market and examine the impact of potential DTCA on the physician-patient relationship, especially, satisfaction, trust and commitment within the Jordanian health market.

Design/Methodology/Approach - A purposive sampling technique was employed to recruit 50 physicians representing the desired range of demographic characteristics (e.g. age, educational level, type of medical specialty, and experience in health services sector).

Findings - This research showed that if the Jordanian health market adopts DTCA techniques it will result in a negative effect on the Jordanian physician-patient relationships.

Originality/value - The research uniquely examines concept of DTCA and proposes how they might be applied to health and pharmaceutical industry in Jordan. It proposes new areas for research relating to the definition of DTCA in the health industry, the paper also makes key recommendations towards the new concept of DTCA.
\end{abstract}

Keywords: DTCA, Physician-patient relationship, Satisfaction, Trust, Commitment, Jordan

\section{Introduction}

The pharmaceutical industry has been slow in adopting Direct-to-Consumer Advertising (DTCA) techniques. The only two developed countries where DTCA is currently legal are the U.S. and New Zealand (Mintzes et al, 2002). While banned elsewhere, the drug industry is mounting major lobbying campaigns to have DTCA allowed in Europe and other countries around the world (Mintzes et al, 2002).

DTCA refers to advertisements that are directed to patients, the final consumers of the pharmaceutical product. In the USA, the Food and Drug Administration (FDA) permits three different types of DTCA (Chen and Carroll, 2007). First, product-claim advertisements, which mention the name of the drug, outline its use, and describe the risks and benefits, in addition to discussing the medical condition it treats; help-seeking advertisements, which discuss the medical condition but do not mention a specific drug product; and reminder advertisements, which provide the name of the drug but do not discuss its uses, risks, or benefits, nor the medical condition it treats.

DTCA can empower patients, who, in the past, have received prescriptions from physicians with little knowledge of prescription drug choices. DTCA has thus changed the pharmaceutical landscape such that doctors no longer are perceived as omnipotent (Deshpande et al, 2004) and prescription drugs advertised directly to consumers have become the largest and fastest selling medicines (Herzenstein et al, 2004). The World Health Organization (WHO) defines drug promotion as: "all informational and persuasive activities by manufacturers 
and distributors, the effect of which is to induce the prescription, supply, purchase and/or use of medicinal drugs".

The relationship between DTCA and physician-patient relationship has emerged as an area of significant and strategic concern for physicians, patients, and pharmaceuticals companies. Many empirical studies (Viale and Yamamoto, 2004; Kravitz, 2005; Joseph et al, 2008; Kalyanaram, 2009) found that there is a positive and significant relationship between DTCA and physician-patient relationships. On the other hand, some studies found that there is a negative and significant relationship between DTCA and physician-patient relationships (Committee on Drugs, 1991; American Medical Association, 1993; Bell et al, 1999; Woloshin et al, 2001; Calfee, 2002; Lexchin and Mintzes, 2002; Murry et al, 2003; Jeffords, 2004; Aikin et al, 2004; Robinson et al, 2004; Kleinke, 2004; Kaphingst, 2005; American College of Physicians, 2005; Brockenbrough, 2007; Spake and Joseph, 2007; Mathew et al, 2008). DTCA advertising is just one strand in the marketing and PR efforts of drug companies to promote brand-name prescription drugs.

This research aims at contribute to the study of pharmaceutical and health services promotion by examining the relationship between DTCA and the physician-patient relationship in the business environment of a developing country. We take up the case of the pharmaceutical industry in Jordan. This research has been built upon previous research's studies to gain empirical insights into the pharmaceutical and health services sectors of Jordan, and to examine the positive and negative effects of DTCA on the patient-physician relationship.

\section{Literature Review}

\subsection{DTCA}

\subsubsection{The Pros and Cons of DTCA}

The drug industry argues that DTCA advertising helps "educate" consumers of potential conditions and encourages them to see their doctor for diagnosis and treatment (Wilkes et al, 2000). While acknowledging that DTCA increases the amount spent on prescription drugs, they argue that in the long run early treatment and diagnosis reduces spending on other medical services, such as hospitalization (Wilkes et al, 2000).

Critics of DTCA argue that the industry's advertising is primarily emotional in style and understates the adverse side-effects and as such are misleading. The imagery of the ads is appealing while the potentially serious side effects are buried in the fine-print (Hoffman and Wilkes, 1999; Mintzes, et al, 2001; Mintzes, 2002; Lexchin and Mintzes, 2002; Donohue et al, 2007). They also (Hoffman and Wilkes, 1999; Mintzes, et al, 2001; Mintzes, 2002; Lexchin and Mintzes, 2002; Donohue et al, 2007) argue that the claimed health benefits are overstated. Surveys reveal that people who have seen DTCA advertisements will often request and be prescribed the drug. DTCA campaigns usually aim to 'pre-prime' doctors via a parallel promotional campaign. As a result, the overall cost of healthcare is unnecessarily driven up without necessarily improving the health of those treated.

The benefits and drawbacks of DTCA are currently being debated within the policymaking arena. Given the success of DTCA in increasing sales, huge profits are at stake for pharmaceutical companies if they can successfully block future anti-DTCA legislation (Viale and Yamamoto, 2004).

Proponents of DTCA claim that it affords patients a myriad of benefits (e.g. Viale and Yamamoto, 2004; Kravitz, 2005; Joseph et al, 2008; Kalyanaram, 2009). They claim that direct, targeted advertisements provide an important source of educational material for patients regarding diseases and available treatments. Thus, patients would be better informed, increasing the likelihood if their seeking treatments for previously untreated ailments, thereby increasing overall public health.

Supporters (Kravitz, 2005; Joseph et al, 2008; Kalyanaram, 2009) also contend that DTCA fosters a new sense of patient empowerment and personal responsibility for individual health by bridging the information gap that previously existed between patients and their doctors. Better educated patients, the argument goes, will be able to make smarter, patient-centered decisions regarding their own health care.

Woloshin et al (2001) show that DTCA information provides patients with an incomplete and biased "education". Nearly 87 percent of television advertisements present the potential benefits of medications in vague, qualitative, terms that are not backed by scientific data.

Kaphingst (2005) shows that most television advertisements present the benefits of drugs at a sixth-grade reading level that most people can understand. The risks, however, are presented at a more difficult to understand ninth-grade level. Such misrepresentations of information suggest that pharmaceutical companies may not be purely interested in "educating" patients through the use of DTCA. 
Opponents of DTCA (Bell et al, 1999; Jeffords, 2004) argue that most advertisements are filled with inaccuracies and misrepresentations. Fundamentally, critics of DTCA contend that it is impossible for pharmaceutical companies to create advertisements that both fully educate patients about medicines and treatments and maximize pharmaceutical sales.

Opponents, such as (Murray et al, 2003; Aikin et al, 2004; Robinson et al, 2004) have also contended that misinformed patients often make unreasonable demands for inappropriate tests and treatments. Physicians must spend a larger proportion of precious office visit time explaining why heavily marketed drugs and treatments are not appropriate rather than focusing on the patient's disease process. Such counseling sessions can significantly and unnecessarily lengthen the office visit and put undue strain on the doctor-patient relationship. Ultimately, critics argue, DTCA encourages often inappropriate patient demands for the latest, most costly, and most heavily marketed drugs or devices. The growing use of such treatments can lead to a misallocation of resources and increase overall healthcare costs.

Brockenbrough (2007) argues that while direct-to-consumer advertisements may help patients make medical decisions; a recent investigation shows that the ads may adversely affect orthopedic surgeons' practices and patient relationships. She also found that over $75 \%$ of surgeons reported that direct-to-consumer (DTC) advertising negatively impacted their practice and the relationship with patients. Similarily, Kleinke (2004) found that physicians, health insurance providers, and managed care organizations have largely held a negative view of DTC advertising. The position of the medical community has generally been that patient education is best provided by physicians, not pharmaceutical companies via the mass media.

In the whole, main concerns among the medical community have been that DTC advertising will "create an inappropriate demand for medications and/or a demand for inappropriate medications, neither of which is in the best interests of the patient" (Committee on Drugs, 1991, p. 174), and harm the doctor-patient relationship (Bell et al, 1999) changing it from a physician-patient relationship into a physician-consumer relationship (Hollon, 1999). Health insurance and managed care organizations have complained that DTC advertising shapes consumer preference for more expensive branded drugs, when other brands or generics are therapeutically comparable (Calfee, 2002) or perhaps even superior.

Both the American Medical Association (AMA) and the American College of Physicians (ACP) have issued statements concerning DTC. The ACP has voiced opposition to DTC advertising on grounds that it undermines the patient-physician relationship and challenges physicians' medical judgment (American College of Physicians, 2005). While the AMA considers DTC advertising acceptable so long as it adheres to AMA guidelines developed in consultation with the FDA (American Medical Association, 1993). The American College of Physicians feels that DTCA "is not a proper practice" and "undermines the patient-physician relationship" (American College of Physicians-American Society of Internal Medicine, 1998). However, surveys conducted by Weissman et al (2004) of physicians show a mixed picture. Some physicians appreciate DTCA for increasing patients' awareness, encouraging patients to seek medical advice for conditions that might otherwise go untreated, and improving doctor-patient communication (Allison-Ottey et al, 2002). Joseph et al (2008) add to the literature by measuring relevant consumer attitudes towards DTCA and the role of income. They found that consumer attitudes toward DTCA appeared to be positive but most consumers were reluctant to admit, or were not aware, that DTCA did influence their behavior or brand preferences. While fewer consumers consider their physicians as their sole source of pharmaceutical information, more and more consumers have begun to rely on DTCA when making healthcare choices. These phenomena tend to cause changes in "physician-patient interaction" and raise public policy concerns. Furthermore, the authors found that DTCA has greater impact on lower income consumers than higher income ones in influencing medical decisions. While DTCA encourages low-income consumers to seek medical treatment, these groups can least afford to buy the expensive, branded drugs that it promotes.

Kalyanaram (2009) suggests a positive and significant effect of DTCA on market share when advertising decision is modeled as an endogenous decision. The empirical results also suggest brand switching by consumers, thus offering empirical support for the argument advanced by medical insurers and providers that DTCA advertising encourages brand switching.

Lee-Wingate and Xie (2010) examined the effectiveness of DTCA based on consumer perceptions of persuasive intent and informativeness associated with product-claim and help-seeking advertisements, respectively. Consumers perceived help-seeking DTCA as being highly informative without persuasive intent, whereas they perceived product-claim DTCA as having high-persuasive intent with little informativeness. Help-seeking 
(versus product claim) DTCA was more effective in generating stronger behavioral intention to seek treatment for the ailments advertised (i.e. clinical depression and migraine).

DeLorme et al (2010) conducted a literature review of over-the-counter (OTC) drug advertising and found public research on OTC drug advertisement to address the following key themes: message placement, message content, consumer response and message effects, and economic effects. Detailed directions for future research on OTC advertising were provided.

Many researchers (Lyles, 2002; Calfee, 2002; Beltramini, 2006) are concerned that, lured by the promise of treatment without seriously considering the potential side effects, DTCA may convince consumers to rely more on prescriptive medicines than necessary (Lyles, 2002). By contrast, many others emphasize that DTCA allows consumers to play a more active role in managing their health (Calfee, 2002) by providing them with education and information about their current or potential medical condition (Beltramini, 2006).

On the one hand, some researchers document negative evidence. For example, Spake and Joseph (2007) find that consumers are skeptical of DTCA; Wosinska (2005) finds that consumers do not necessarily comply with the recommended drug regimen or commit to the advertised brand; and Lexchin and Mintzes (2002) report that DTCA spending is not associated with any improvement in health outcomes. On the other hand, other researchers show that DTCA increases market size and plays an important role in providing health education and treatment information for formerly ignorant consumers (Iizuka and Jin, 2005; Narayanan et al, 2004; Rosenthal et al, 2003; Xie and Krishnamurthi, 2004). Based on the discussed literature review, it can be hypothesized that:

Hypothesis 1: DTCA has a negative significant influence on physician-patient relationship.

DTCA in the Jordanian private practices was measured on:

Hypothesis 2: DTCA has a negative significant influence on patient satisfaction.

Hypothesis 3: DTCA has a negative significant influence on patient trust.

Hypothesis 4: DTCA has a negative significant influence on patient commitment.

\subsection{Physicians-Patient Relationship}

The physician-patient relationship differentially impacts the satisfaction-trust-commitment relationship. Since the caliber of health service is highly dependent on credibility qualities (Zeithaml, 1981; Iacobucci, 1992), patients must rely on what they see (Baker and Lamb, 1992; Paul and Honeycutt, 1996) and how they perceive they are treated (Peltier et al, 2002) when moderating the quality of the care delivered.

Patients with a less amiable disposition would prefer to decrease social interaction (Hills and Argyle, 2001), and consequently will need stronger evidence that their physician is able to deliver high quality care. In contrast, a sociable patient is likely to value social interaction as a key component in forming perceptions of how they are treated (Peltier et al, 2002), and judge the health provider on the basis and quality of social interaction in addition to evidence of provider competence, when evaluating the health service experience.

\subsubsection{Satisfaction, Trust, and Commitment}

The roles of satisfaction, trust, and commitment, and the relationships among these builds, have often been studied in research involving customer relationship marketing (Garbarino and Johnson, 1999; Palmatier et al, 2006). Trust and commitment are important factors in physician-patient relationship development (Morgan and Hunt, 1994) and all three builds play a role in customer/patient retention (Garbarino and Johnson, 1999), including patient retention in health services settings (Crutchfield, 2001).

Spake et al (2003) found that satisfaction had a direct impact on trust, and trust a direct impact on commitment across two service contexts, including health care. Garbarino and Johnson (1999) found that overall satisfaction was the primary mediating construct between satisfaction with components of the experience and future intentions to attend, subscribe, and donate for low relational customers. Hence, it appears that satisfactory transactions increase the chance that the customer will remain with the seller. Customers use snowballing experience when making judgments about the seller and these cumulative experiences become transaction-specific assets that provide the partners with shared private knowledge that connect these individuals (Reagans et al, 2005).

\section{Research Objectives}

Based on the research problem and relevant literature of the DTCA, physician-patient relationship, and satisfaction, trust and commitment, the research objectives are: 
1). To determine the factors which constitute the physician-patient relationship and DTCA components in the Jordanian health market

2). To examine the relationship between the DTCA and physician-patient relationship with regard to satisfaction, trust, and commitment

\section{Research Methodology}

\subsection{Population and Sample}

This research is a descriptive and analytical study that describes the nature of the relationship between the DTCA and how DTCA will affects the patient-physician relationship.

The research population in this study consists of physicians in the Jordanian private practice health sector. The research sample was selected from the customer database of Glasgow Smith Klein (GSK), Jordan. All of the research respondents were of $(\mathrm{A})$ to $(\mathrm{B}+)$ class which means that the physician meets more the 50 patients per week. Fifty physicians were included in this research.

The researchers gathered 50 questionnaires, yielding a response rate of $100 \%$. All data collection procedures were designed to ensure the anonymity. Respondents typically held purposive sample. It should be noted that every questionnaire was personally handed and instructions were given to each physician before completing the questionnaire. Regarding to educational levels of those physicians $(50.9 \%)$ were master degree holders, and the remaining $(49.1 \%)$ were bachelor degree holders. In terms of the age group of respondents, it is interested to note that $(47.3 \%)$ of them are fell into (41-50) years, whereas (14.5\%) are over 60 years old. In terms of the type of medical specialty of those physicians, the majority (36.6\%) were surgical specialty, and some those (36.4\%) of these, were medical specialty. As for the experience of health service sector of those physicians, were most of them $(85.5 \%)$ were over 20 years experience. See table (4).

\subsection{Data Collection}

The research questionnaire was designed on the formats of previous empirical literature. The questionnaire design was pre-tested and redesigned through personal interviews with physicians from different sectors customers by undertaking the pilot study work (Aaker et al, 2001).

The research questionnaire was used as primary data collection method. The components of DTCA and physician-patient items were measured on 5-point Likert- scale ranging from 5 (strongly agree) to 1 (strongly disagree). For the DTCA and physician-patient dimensions, the research respondents were asked to indicate the degree of agreement or disagreement on the DTCA items that DTCA used in order to achieve physician-patient satisfaction, trust, and commitment. Consistent with the literature, the scale items selected for the dependent variable were direct measures of physician-patient relationship with influences received from adoption of DTCA as independent variables. This format has been recommended for marketing and health services surveys.

Both the independent and dependent variable(s) deployed in the research are explained in Table 1 and 2 according to the proposed hypotheses.

\section{Results and Discussion}

\subsection{Major Hypothesis Testing Results}

The basic assumptions are that DTCA items influence the physician-patient relationship, namely satisfaction, trust, and commitment. A multiple regression modeling approach was proposed as an effective method for studying the relationships. Table (3) presents the results of regression analysis. The results indicate that there are negative significant impacts of overall DTCA on overall physician-patient relationship (PPR) $(\beta=-0.608)$ and $(\mathrm{t}$-value $=-5.575)$ as shown in research model. The research model shows that $(\mathrm{R} 2=0.468, \mathrm{p}<0.05)$. This means that overall DTCA explains around 47 percent of the variance in satisfaction indicates that approximately 46 percent of the variance in (PPR) can be accounted for by the DTCA variables. The results of the regression analysis show that DTCA affects the (PPR). Hence, the null hypothesis is accepted.

In addition, it is predicted that the influence of such DTCA factors on satisfaction, trust, and commitment would differ according to the personal variables, which are personal characteristics and their experience in computers (as shown in table 4).

This empirical evidence has provided significant support for the DTCA literature, which substantively advocates that DTCA items have a negative impact on physician-patient relationship. 
The results empirically substantiate that DTCA items play a fundamental role in the relationship among Jordanian physicians. There is a negative significant relationship between the DTCA and the physician-patient relationship.

\subsection{Minor Hypothesis 2 Testing Result}

There is a negative significant relationship between the DTCA and the physician-patient satisfaction.

Empirically, the model assumed that DTCA items negatively influence physician-patient satisfaction in the Jordanian health sector. In addition, it predicted that the influence of such factors on physician-patient satisfaction would differ according to the personal variable which is age, education level, medical specialty, and experience in the health sector (table 4). The results on table (3) show that there are a statistical negative significant impact of overall DTCA on Satisfaction $(\beta=-0.563)$ and (t-value $=-4.964)$. The research model shows that $(\mathrm{R} 2=0.317, \mathrm{p}<0.05)$ this means that overall DTCA explains 31 percent of the variance in Satisfaction. The results of the regression analysis show that DTCA affects satisfaction; thus the result provides support for the minor hypothesis 1a. Consequently, the null hypothesis is accepted.

The results empirically substantiate that DTCA items play a fundamental role in satisfaction among Jordanian physicians.

\subsection{Minor Hypothesis 3 Testing Result}

There is a negative significant relationship between DTCA and the physician-patient trust.

The basic assumption is that DTCA items negatively influence physician-patient relationship in terms of trust. A multiple regression modeling approach was proposed as an effective method for studying the relationships. The results on table (3) show that there is a statistically significant impact of overall DTCA on trust $(\beta=-0.446)$ and $(\mathrm{t}-\mathrm{value}=-3.625)$. The research model shows that $(\mathrm{R} 2=0.199, \mathrm{p}<0.05)$. This means that overall DTCA explains 19 percent of the variance in trust. The results of the regression analysis show that DTCA affects trust thus providing support for the minor hypothesis $1 \mathrm{~b}$. Therefore, the null hypothesis is accepted.

This empirical evidence has provided significant support for DTCA literature, which substantively advocates that DTCA items have an impact on physician-patient trust.

The results empirically confirm that DTCA items play a fundamental role in trust, among Jordanian physicians.

\subsection{Minor Hypothesis 4 Testing Result}

There is a negative significant relationship between the DTCA and the physician-patient commitment.

The model assumed that DTCA items negatively influence physician-patient commitment in the Jordanian health sector. In addition, it predicted that the influence of such factors on physician-patient commitment would differ according to the personal variables like age, education level, medical specialty, and experience in health sector (Table 4). The results in table (3) show that there is a statistically significant impact of overall DTCA on commitment $(\beta=-0.576)$ and ( $\mathrm{t}$-value $=-21.408)$. The research model shows that $(\mathrm{R} 2=0.469, \mathrm{p}<0.05)$. This means that overall DTCA explains 46 percent of the variance in commitment and the results of the regression analysis show that DTCA affects commitment. Thus the result provides support for the minor hypothesis $1 \mathrm{c}$. Hence, the null hypothesis is accepted.

This empirical evidence has provided significant support for DTCA literature, which substantively advocates that DTCA items have a negative impact on physician-patient commitment.

The results empirically confirm that DTCA items play a fundamental role in the commitment among Jordanian physicians.

In summary, it can be seen that all DTCA items, have proven to negatively influence the physician-patient relationship, namely, satisfaction, trust, and commitment.

\section{Implications}

The theoretical groundwork of this research is based on literature from DTCA relating to the physician-patient relationship within the pharmaceutical and health services industries. DTCA has multifaceted effects on the physician-patient relationship. It results in patients making almost as many inappropriate requests as appropriate ones. This puts physicians in a dilemma, especially with respect to advice and decisions on the one side and ethical obligations on the other. Physicians seek to maintain and develop a strong doctor-patient relationship because it enhances future healthcare and health services outcomes. The empirical conclusions drawn from this research are many-sided and as a result, it is crucially significant that pharmaceutical companies pay attention to the influences created by DTCA on physician-patient relationships (satisfaction, trust, and commitment). 
Researchers are therefore encouraged to place more emphasis on the impact of influences stemming from DTCA, and its impact on physician-patient relationships within Jordanian pharmaceutical and health services industries.

\section{Conclusion}

This study potentially contributes to knowledge by examining the impact of DTCA items on physician-patient relationships within the Jordanian pharmaceutical and health services industries. The research also contributes to the health services marketing discipline in investigating the role played by DTCA in enhancing physician-patient relationships within the Jordanian health market.

This study could be useful for academics, medical practitioners, and pharmaceutical company managers alike. Academically, this work aims to focus academic attention on a much neglected domain - the health services marketing, health promotion, and pharmaceutical companies in Jordan. There is currently a lack of appropriate study on this subject by academia in the Middle East.

In fact, the health services industry is a highly significant and thriving sector in Jordan, and health service provider practices are considered as an important segment of the health services industry where patients are offered a wide range of medical services.

Although this research has provided precious insights into a somewhat scant area of research, it is been subject to some limitations. Some difficulties were encountered in this research because it was considered to be a new concept. Also there were no practical applications of this tool in Jordan and the Arab region possibly leading to some inconsistencies in the data collection process. Future research shall therefore be required to extend these results to other sectors (e.g. Ministry of Health, Royal Medical Services, and teaching hospitals), and among physicians working in hospitals. The concept could also be extended to other Arab countries in the regions in order to validate the models and findings. Future research should also investigate whether the model could be used for different dependent variables e.g. health service quality, financial performance, and market share.

\section{References}

Aikin, K., Swasy, JL., \& Braman, A. (2004). Patient and Physician Attitudes and Behaviors Associated with DTC Promotion of Prescription Drugs: Summary of FDA Survey Research Results. Rockville, MD, Center for Drug Evaluation and Research, Food and Drug Administration, US Department of Health and Human Services.

Allen, F., McAndrews, J., \& Strahan, P. (2001). E-finance: An Introduction, working paper No. 01-36. Financial Institutions Center, Wharton University, Philadelphia, PA, 7 October.

Allison-Ottey, D., Ruffin, K., \& Allison, K. (2002). To do no harm: survey of NMA physicians regarding perceptions on DTC advertisements. Journal of the National Medical Association, 94, (4), 194-202.

American College of Physicians. (2005). Statement of the American College of Physicians for the record of the public hearing on consumer-directed promotion of regulated medical products. [Online] Available: http://www.acponline.org/hpp/dtc_fda.pdf (April 26, 2006).

American College of Physicians-American Society of Internal Medicine. (1998). Direct-To-Consumer Advertising for Prescription Drugs. Philadelphia, PA.

American Medical Association. (1993). H-105.988 direct-to-consumer advertising (DTCA) of prescription drugs. [Online] Available: http:// www.ama.org

Anderson, E., \& Sullivan, W. (1993). The antecedents and consequences of customer satisfaction for firms. Marketing Science, 12, (2), 125-43. http://dx.doi.org/10.1287/mksc.12.2.125

Avorn, J. (2003). Advertising and prescription drugs: promotion, education, and the public's health. Health Affairs, 22, (1), 104-108.

Baker, J., \& Lamb, Jr. (1992). Physical environment as a hospital marketing tool. Journal of Ambulatory Care Marketing, 5, (1), 59-69.

Bell, A., Kravitz, L., \& Wilkes, M. (2000). Direct-to-consumer prescription drug advertising, 1989-1998: a content analysis of conditions, targets, inducements, and appeals. Journal of Family Practice, 49, (4), 329-335.

Bell, RA., Kravitz, RL., \& Wilkes MS. (1999). Direct-to-consumer prescription drug advertising and the public. Journal of General Internal Medicine, 14, (11), 651-657. http://dx.doi.org/10.1046/j.1525-1497.1999.01049.x

Beltramini, F. (2006). Believability of direct to consumer (DTC) advertising of pharmaceutical products. Journal of Business Ethics, 63, (4), 333-43. http://dx.doi.org/10.1007/s10551-005-4711-2 
Brockenbrough, G. (2007). Most hip, knee surgeons say DTC ads weaken doctor/patient relationships: Survey questions the value of ads in educating patients, promoting new surgical techniques.

Calfee, E. (2002). Public policy issues in direct-to-consumer advertising of prescription drugs. Journal of Public Policy and Marketing, 21, (2), 174-93. http://dx.doi.org/10.1509/jppm.21.2.174.17580

Canadian Pharmacists Association. (2000). Position Statement on Direct-to-Consumer Advertising (DTCA), Approved by CPhA Board of Directors - February.

Chen, D., \& Carroll, V. (2007). Consumer responses to direct to consumer prescription drug advertising. International Journal of Pharmaceutical and Healthcare Marketing, 1, (4), 276-89. http://dx.doi.org/10.1108/17506120710840134

Committee on Drugs. (1991). Prescription drug advertising direct to the consumer. Pediatrics, 88, (1), 174-5.

Crutchfield, N. (2001). The effect of trust and commitment on retention of high-risk professional service customers. Services Marketing Quarterly, 22, (2), 17-27. http://dx.doi.org/10.1300/J396v22n02_02

Deshpande, A., Menon, A., Perri, M., \& Zinkhan, G. (2004). Direct to consumer advertising and its utility in healthcare decision making. Journal of Healthcare Communication, 9, 499-513. http://dx.doi.org/10.1080/10810730490523197

Donohue, J., Cevasco, M., \& Rosenthal, M. (2007). A Decade of Direct-to-Consumer Advertising of Prescription Drugs. New England Journal of Medicine, 16, (7), 673-681. http://dx.doi.org/10.1056/NEJMsa070502

Garbarino, E., \& Johnson, M. (1999). The different roles of satisfaction, trust, and commitment in customer relationships. Journal of Marketing, 63, (2), 70-87. http://dx.doi.org/10.2307/1251946

Herzenstein, M., Misra, S., \& Posavac, S. (2004). How Consumers' Attitudes Toward Direct-to-Consumer Advertising of Prescription Drugs Influence Ad Effectiveness, and Consumer and Physician Behavior. Marketing letters, 15, (4), 201-212. http://dx.doi.org/10.1007/s11002-005-0458-x

Hills, P., \& Argyle, M. (2001). Happiness, introversion extraversion and happy introverts. Personality Individual Differences, 30, (4), 595-608. http://dx.doi.org/10.1016/S0191-8869(00)00058-1

Hoffman, J., \& Wilkes, M. (1999). Direct to consumer advertising of prescription drugs, Editorial. British Medical Journal.

Hollon, M. (1999). Direct-to-consumer marketing of prescription drugs: creating consumer demand. The Journal of the American Medical Association, 281, (4). http://dx.doi.org/10.1001/jama.281.4.382

Iacobucci, D. (1992). An empirical examination of some basic tenets in services: goods-services continua. In Swartz, T., Bowen, D.E. and Brown, S.W. (Eds), Advances in Services Marketing and Management, 1. JAI Press, Greenwich, CT, 23-52.

Iizuka, T., \& Jin, G. (2005). The effect of prescription drug advertising on doctor visits. Journal of Economics \& Management Strategy, 14, (3), 701-27. http://dx.doi.org/10.1111/j.1530-9134.2005.00079.x

Jeffords, JM. (2004). Direct-to-consumer drug advertising: You get what you pay for. Health Affairs (Millwood). Suppl Web Exclusives: W4-pp253-255.

Kaphingst, A., Dejong, W., Rudd, E., \& Daltroy, H. (2004). A content analysis of direct-to-consumer television prescription drug advertisements. Journal of Health Communication, 9, (6), 515-28. http://dx.doi.org/10.1080/10810730490882586

Kaphingst, KA., \& Rudd, R., \& Dejong, W. (2005). Comprehension of information in three direct-to-consumer television prescription drug advertisements among adults with limited literacy. Journal of Health Commune, 10, (7), 609-619. http://dx.doi.org/10.1080/10810730500267647

Kleinke, J. (2004). Access Versus Excess: Value-Based Cost Sharing For Prescription Drugs, Health Affairs, 23, No. 1, pp34-47. http://dx.doi.org/10.1377/hlthaff.23.1.34

Lexchin, J., \& Mintzes, B. (2002). Direct-to-consumer advertising of prescription drugs: The evidence says no. Journal of Public Policy and Marketing, 21, (2), 194-202. http://dx.doi.org/10.1509/jppm.21.2.194.17595

Mathew, J., Deborah, F., \& Spake, F. (2008). Consumer attitudes toward pharmaceutical direct-to-consumer advertising: An empirical study and the role of income. International Journal of Pharmaceutical and Healthcare Marketing, 2, (2), 117 - 133. http://dx.doi.org/10.1108/17506120810887916 
Mintzes, B., Barer, M., Kravitz, R., Kazanjian, A., Bassett, K., Lexchin, J., Evans, R., Pan, R., \& Marion, S. (2002). Influence of direct to consumer pharmaceutical advertising and patients' requests on prescribing decisions: two site cross sectional survey. British Medical Journal.

Mintzes, B., Kazanjian, A., Bassett, K., \& Lexchin, J. (2001). Pills, persuasion and public health policies: Report of an expert survey on direct to consumer advertising of prescription drugs in Canada, the United States and New Zealand. Centre for Health Services and Public Policy, University of British Columbia.

Mintzes, M. (2002). For and against: Direct to consumer advertising is medicalising normal human experience. British Medical Journal.

Morgan, M., \& Hunt, S. (1994). The commitment trust theory of relationship marketing. Journal of Marketing, 58, (3), 20-38. http://dx.doi.org/10.2307/1252308

Murray, E., Lo, B., Pollack, L., \& Donelan, K. (2003). Direct-to-consumer advertising: Physicians views of its effects on quality of care and the doctor-patient relationship.

Narayanan, S., Desiraju, R., \& Chintagunta, P. (2004). Return on investment implications for pharmaceutical promotional expenditures: the role of marketing-mix interactions. Journal of Marketing, 68, 90-105. http://dx.doi.org/10.1509/jmkg.68.4.90.42734

Palmatier, W., Dant, P., Grewal, D., \& Evans, R. (2006). Factors influencing the effectiveness of relationship marketing: a meta-analysis. Journal of Marketing, 70, (4), 136-53. http://dx.doi.org/10.1509/jmkg.70.4.136

Paul, P., \& Honeycutt, E., Jr. (1996). Health care marketing: doctors to patients and hospitals to doctors. Journal of Hospital Marketing, 11, (1), 65-79. http://dx.doi.org/10.1300/J043v11n01_06

Peltier, W., Schibrowsky, J., \& Cochran, R. (2002). By now it's accepted. Marketing Health Services, 22 (2), 29-33.

Petroshius, M., Titus, A., \& Hatch, J. (1995). Physician attitudes toward pharmaceutical drug advertising. Journal of Advertising Research, 35, (6), 41-51.

Reagans, R., Argote, L., \& Brooks, D. (2005). Individual experience and experience working together: predicting learning rates from knowing who knows what and knowing how to work together. Management Science, 51, (6), 869-881. http://dx.doi.org/10.1287/mnsc.1050.0366

Robinson, AR., Hohmann, KB., \& Rifkin, JI. (2004). Direct-to-consumer pharmaceutical advertising: Physician and public opinion and potential effects on the physician-patient relationship. Archives of Internal Medicine, 164, (4), 427-432. http://dx.doi.org/10.1001/archinte.164.4.427

Rosenthal, B., Berndt, R., Donohue, M., Epstein, A., \& Frank, G. (2003). Demand effects of recent changes in prescription drug promotion. Frontiers in Health Policy Research, (6) 1-26.

Spake, F., \& Joseph, M. (2007). Consumer opinion and effectiveness of direct-to-consumer advertising. Journal of Consumer Marketing, 24, (5), 283-92. http://dx.doi.org/10.1108/07363760710773102

Spake, F., Beatty, E., Brockman, K., \& Crutchfield, N. (2003). Consumer comfort in service relationships: measurement and importance.

Weissman, S., Blumenthal, D., Silk, J., Newman, M., Zapert, K., Leitman, R., \& Feibelmann, S. (2004). Physicians report on patient encounters involving direct-to-consumer advertising. Health Affairs. [Online] Available: http://content.healthaffairs.org/cgi/content/abstract/hlthaff.w4.219v1

Wilkes, R., Bell, A., \& Kravitz, R. (2000). Direct-to-consumer prescription drug advertising: trends, impact, and implications. Health Affairs, 19, (2), 110-128. http://dx.doi.org/10.1377/hlthaff.19.2.110

Woloshin, S., Schwartz, M., \& Tremmel, J. (2001). Direct-to-consumer advertisements for prescription drugs: What are Americans being sold? Lancet 358, (9288), 1141-1146. http://dx.doi.org/10.1016/S0140-6736(01)06254-7

World Health Organization. (1997 a). Cross-border advertising, promotion and sale of medical products using the Internet. WHA Resolution, May, 12.

World Health Organization. (1997 b). Cross-border advertising, promotion and sale of medical products using the Internet. The report of the ad hoc working group on cross-border promotion, advertising and sale of medical products using the Internet. Sept (Draft Report).

Wosinska, M. (2005). Direct-to-consumer advertising and drug therapy compliance. Journal of Marketing Research, 42, (3), 323-32. http://dx.doi.org/10.1509/jmkr.2005.42.3.323 
Xie, Y., \& Krishnamurthi, L. (2004). The impact of DTC advertising and physician promotions on treatment incidence and brand choice decisions. Rutgers Business School, Rutgers University, Lakewood, NJ, working paper.

Zeithaml, A. (1981). How consumer evaluation processes differ between goods and services. In Donnelly, J.H. and George, W.R. (Eds), Marketing of Services, American Marketing Association, Chicago, IL, 186-9.

Table 1. DTCA

Hypothesis 1: DTCA has a negative significant influence on physician-patient relationship.
DTCA in the Jordanian private practices was measured on:
DTCA will expand the use of the local pharmaceutical brands, DTCA will expand the use of the
international pharmaceutical brands, DTCA will reinforce the pharmaceutical products promoted,
DTCA will help the pharmaceutical companies to introduce and position a new brands, DTCA will
improve doctor-patient relationship, DTCA will influence the number of patients visit to your clinic,
DTCA will lead physician perceived improved communication and education, DTCA will lead
patients seek unnecessary treatment, DTCA will suggested other alternative treatments, DTCA will
help patient to ask about a specific prescription drug by brand name, DTCA will make patient ask you
for a prescription, DTCA help patients to reduce anxiety about potential diseases, DTCA help
patients to reduce anxiety about potential side effects, DTCA will creates tension between you and
your patients, DTCA increase awareness (aware of problems earlier, aware of possible treatments),
DTCA will increases drug costs due to the need to pay for promotions, DTCA will cause unsafe
practices among consumers, DTCA will make the market for pharmaceuticals more efficient,
DTCA are funded by pharmaceutical companies and, therefore, lack objectivity, DTCA will help
patients to learn about particular disease, DTCA will help patients to learn about particular medication
or drugs, DTCA will reduce discuss their cases with doctors, DTCA will make patients decide which
drug is right, DTCA will help patients to get a second opinion, DTCA will help patients to request
more information from doctor, DTCA will make you feel that pressured to prescribe inappropriate
medications.

Table 2. Patient satisfaction, trust, and commitment

Hypothesis 2: DTCA has a negative significant influence on patient satisfaction.

The measure for this factor consists of: Please evaluate your patient based on all the experiences you have had with this person, Delight, satisfied, dissatisfied.

Hypothesis 3: DTCA has a negative significant influence on patient trust.

The patient trust was assessed by measuring: My patient can be trusted completely, can be counted on to do what is right, is someone that I have great confidence in, Can be relied on.

Hypothesis 4: DTCA has a negative significant influence on patient commitment.

The measurement of commitment was assessed by: The relationship that I have with my patient is something I am very committed to, is very important to me, is something I would like to maintain for a long time, is something I really care about, deserve my maximum effort to maintain. 
Table 3. Simple regression results

\begin{tabular}{|l|c|c|c|c|c|c|c|c|}
\hline \multirow{4}{*}{} & \multicolumn{9}{|c|}{ Dependent Variables } \\
\cline { 2 - 8 } & \multicolumn{2}{|c|}{$\begin{array}{c}\text { Physician-Patient } \\
\text { Relationship }\end{array}$} & \multicolumn{2}{|c|}{ Satisfaction } & \multicolumn{2}{c|}{ Trust } & \multicolumn{2}{c|}{ Commitment } \\
\cline { 2 - 9 } & Beta & t-value & Beta & t-value & Beta & t-value & Beta & t-value \\
\hline $\begin{array}{l}\text { DTCA } \\
\text { control } \\
\text { Variables }\end{array}$ & -0.608 & -5.575 & -0.563 & -4.964 & -0.446 & -3.625 & -0.576 & -21.408 \\
\hline
\end{tabular}

Table 4. Characteristics of the sample $(\mathrm{N}=50)$

\begin{tabular}{|l|c|}
\hline \multicolumn{1}{|c|}{ Characteristics } & Percent \\
\hline Age: & \\
$41-50$ & 47.3 \\
$51-60$ & 38.2 \\
Over 60 & 14.5 \\
\hline Educational Level: & \\
Bachelor's degree & 49.1 \\
Masters degree & 50.9 \\
\hline Type of Medical Specialty: & \\
Medical Specialty & 36.4 \\
Surgical Specialty & 63.6 \\
\hline Experiences in Health Service Sector: & \\
16-20 & 14.5 \\
Over 20 & 85.5 \\
\hline
\end{tabular}




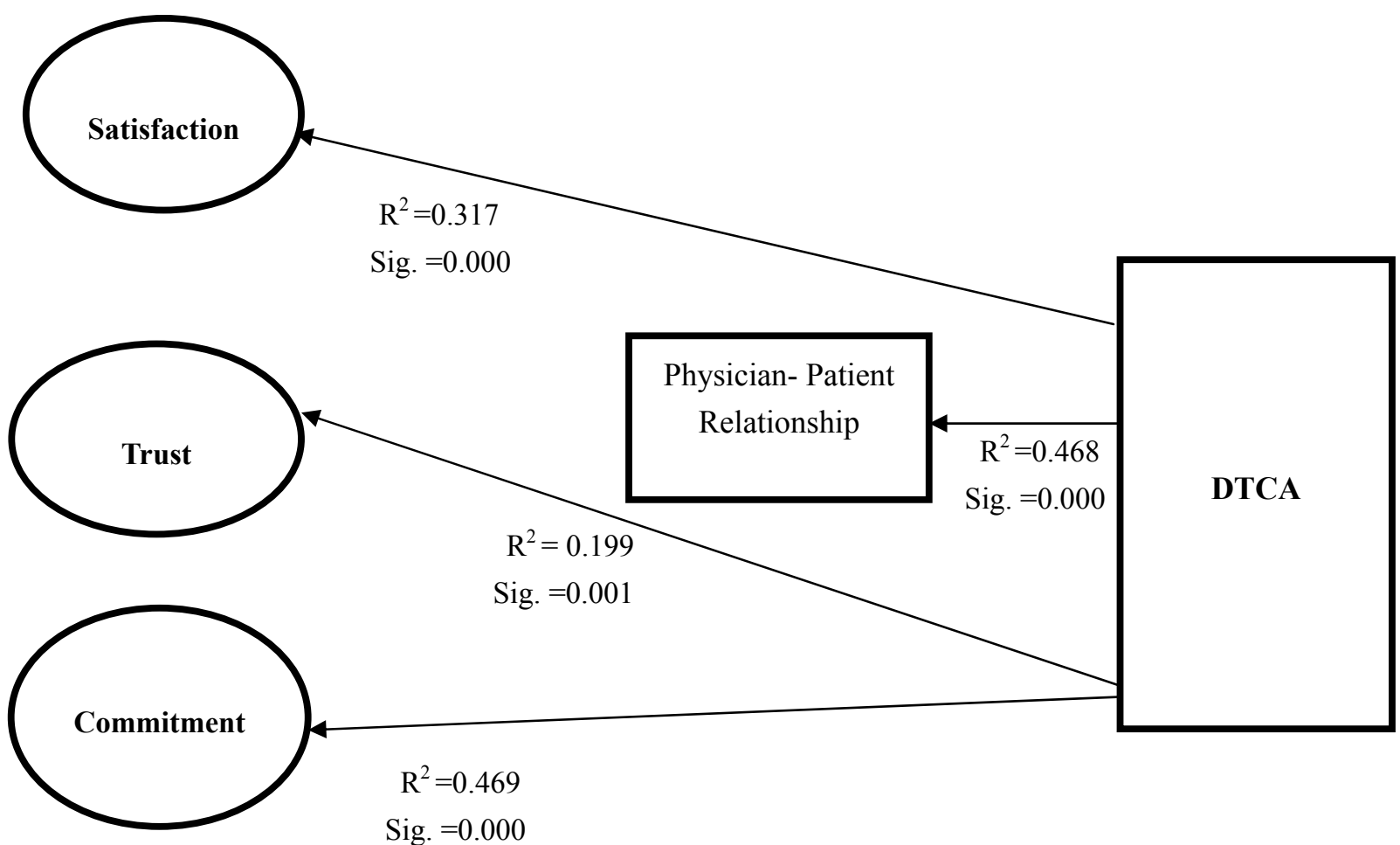

Figure 1. Research model 